\title{
Role of Ultrasonography in The Diagnosis and Management of Endophthalmitis
} in Cats

\author{
Khaled M. Ali* \\ Department of Surgery, Anesthesiology and Radiology, Faculty of Veterinary Medicine, Cairo University. PO: \\ 12211, Giza, Egypt. \\ *Corresponding Author, Khaled M. Ali, E-mail: drkhaled_ali@cu.edu.eg
}

\begin{abstract}
Endophthalmitis is one of the most devastating diagnoses in veterinary and human ophthalmology. Ocular ultrasound is an effective and non-invasive technique used for evaluating the structures of the eye and the surrounding tissues, especially when the development of ocular opacities in conditions such as corneal disease, uveitis, cataracts or trauma prevent or limit the use of ophthalmoscopy and slit-lamp biomicroscopy. The present study aimed to evaluate the ultrasonographic characteristics of endophthalmitis in cats and to assess the usefulness of ultrasonography in the selection of treatment methods in such cases. Sixty cats (90 eyes) of different breeds were presented with bilateral (30 cats) and unilateral (30 cats; $\mathrm{OD}=10$, $\mathrm{OS}=20$ ) endophthalmitis. The mean age $\pm \mathrm{SEM}$ at the initial presentation was $13.46 \pm 1.69$ months (range, $2-72$ months). After a thorough ophthalmic examination, the ultrasonographic evaluation using a high frequency $(7.5-10 \mathrm{MHz})$ micro-convex probe was conducted to evaluate the concurrent ocular abnormalities in the anterior and posterior eye segments. After completing the ultrasonographic examination, the treatment protocol was applied. It was concluded that ocular ultrasonographic evaluation was found suitable in the diagnosis of endophthalmitis in cats and for the selection of the treatment protocol.
\end{abstract}

Original Article:

DOI: $\underline{\text { HTTPS://DX.DOI.ORG/10.21608/JAVS.2 }}$ $\underline{0.98376}$

Received : 28 May, 2020.

Accepted : 17 June, 2020.

Published in July, 2020.

This is an open access article under the ter of the Creative Commons Attribution 4 (CC-BY) International License . To view copy of this license, vi http://creativecommons.org/licenses/by/4.(

Keywords: Cat, Endophthalmitis, retinal detachment, ultrasonography, J. Appl. Vet. Sci., 5(3 ): 57 - 70. vitreous detachment.

\section{INTRODUCTION}

Endophthalmitis is a serious intraocular inflammatory disorder affecting the vitreous cavity that can result from the exogenous or endogenous spread of infecting organisms into the eye (Esson, 2015). The disease is common in cats following corneal perforation after cat claw injury (Spiess $\boldsymbol{e t}$ al., 1996) and from the progression of a deep or melting corneal ulcer (Brooks and Matthews, 2007). Symptoms can be variable, from very little inflammation in the anterior chamber and the anterior portion of the vitreous to extremely painful panopthalmitis with no fundus view, corneal edema, or complete anterior chamber hypopyon (Mamalis et al., 2002).

Ocular ultrasound is an effective and noninvasive technique used to evaluate the eyeball structures and the surrounding tissues (Fielding, 2001). The technique is useful for diagnosing the internal structures of the eye especially when the development of ocular opacities in conditions such as corneal disease, uveitis, cataracts or trauma prevent or limit the use of ophthalmoscopy and slit-lamp biomicroscopy (Scotty et al., 2004 and Mackay and Mattoon, 2015). Ocular ultrasonography allows for the evaluation of structures such as the cornea, anterior chamber, iris, ciliary body, lens, vitreous chamber and the posterior section of the bulbar wall (Nautrup, Tobias, 2000 and Singh et al., 2015). Reviewing the veterinary literature, ocular ultrasonography was utilized for evaluation of the ocular abnormalities in dogs (Daret al., 2014), Buffaloes (Singh et al., 2016) and in horses (Gialletti et al., 2018). In human ophthalmology, many previous literatures have been evaluated ultrasonography in the diagnosis of different ocular diseases and the utility of ocular ultrasonography in diagnosing endophthalmitis was fully described (Marchini et al., 1995 and Kohanim, 2012). For author knowledge, no previous studies were used to evaluate ultrasonographic abnormalities associated with endophthalmitis in cats except for one case report (Guyonnet et al., 2019). 
Therefore, the present study aimed to evaluate the ultrasonographic characteristics of ocular abnormalities associated with endophthalmitis in cats and to assess the usefulness of ultrasonography in the selection of the treatment method in such clinical cases.

\section{MATERIALS AND METHODS}

\section{Animals}

The present study was carried out on sixty pet cats (90 affected eyes) of different breeds and of both sexes. The enrolled cats were examined by the ophthalmology service at the Department of Surgery, Anesthesiology and Radiology, Faculty of Veterinary Medicine, Cairo University, Egypt. Cat's owners were aware that their cats will be used for research purposes and signed a consent indicating their approval. Data collected included signalment, history, duration of clinical signs and ophthalmic examination abnormalities. After complete ophthalmic examination, the inclusion criteria included cats diagnosed with endophthalmitis secondary to hyper mature cataract (phacoanaphylactic endophthalmitis) and buphthalmos iridocyclitis, posterior segment abnormalities or perforating corneal injury.

\section{Ultrasonographic examination}

Prior to ultrasonographic scanning, topical corneal anesthesia was achieved via the installation of benoxate hydrochloride $0.4 \%$ (Douet et al., 2013) (Benox®; EIPICO, Cairo, Egypt). Then highly purified ultrasound gel (Parker Aquasonic 100®, UK) was applied over the eye to be scanned (Mackay and Mattoon, 2015). The cats were restrained in sternal recumbency with head fixated for ultrasonographic scanning. Ultrasonographic scanning was performed gently using a 7.5-10 $\mathrm{MHz}$ micro-convex probe (EDAN DUS 60 PRO, digital ultrasound, Shenzhen, PR China) as described by (Featherstone and Heinrich, 2013 and Mackay and Mattoon, 2015). The ultrasonographic evaluation was carried out by systematically examining the cornea, anterior chamber, lens, iris and ciliary body, vitreous humor, ocular fundus, and retro-bulbar space.

Various scanning planes were used including trans-corneal (axial), trans-scleral and tangential approaches. For general screening, the axial approach or scanning along the central optic axis was used in a transverse and sagittal plane. The trans-scleral approach, which is scanning through the lens, is avoided and used for imaging structures in the posterior segment. In the tangential approach, the transducer was applied against the cornea for better visualization of the anterior structures (Schmid, 2007).

\section{RESULTS}

\section{Animals}

The breeds included in the present study were Domestic shorthair (DSH, $n=30)$, Persian $(n=20)$, Himalayan $(n=5)$, and Siamese $(n=5)$. The mean age \pm SEM at the initial presentation was $13.46 \pm 1.69$ months (range, 2 - 72 months). There were 45 males (30 intact and 15 castrated) and 15 intact females. The mean \pm SEM duration of clinical signs prior to presentation was $9.76 \pm 0.78$ days (range, 2 - 28 days). Both eyes were involved in $30(50 \%)$ cats, the left eye (OS; Oculus Sinister) was affected in $20(33.33 \%)$ cats and the right eye (OD; Oculus Dexter) was involved in $10(16.66 \%)$ cats.

\section{Ophthalmic and ultrasonographic findings}

Based on concurrent ocular abnormalities, the cases of endophthalmitis were categorized into: corneal perforation with keratocoele/or large protruding fibrin clot over the corneal surface, buphthalmos, phacoanaphylactic endophthalmitis and iridocyclitis.

Unresponsive endophthalmitis secondary to corneal perforation was diagnosed in 40 eyes (40/90; $44.44 \%$ ). The cause of corneal perforation was nontraumatic as a progression of deep stromal or melting ulcer in $23(23 / 40 ; 57.5 \%)$ eyes and was traumatic as a result of cat claw injury in $17(17 / 40 ; 42.5 \%)$ eyes. The clinical presentation included corneal vascularization, edema and large protruded fibrin clot over the corneal surface (Figure 1a), corneal melting (Figure 1b), hyphema (Figure 1c) and conjunctival chemosis, keratocoele and collapsed anterior chamber (Figure 1d). The ultrasonographic evaluation revealed intraocular hemorrhage in $20(20 / 40 ; 50 \%)$ eyes, pus inside the eyeball in $10(10 / 40 ; 25 \%)$ eyes and lowreflectivity endovitreal echoes in $10(10 / 40 ; 25 \%)$ eyes.

Intraocular bleeding appeared as amorphous opacities to hypoechoic patchy zones filling the anterior and posterior chamber (Figure 2a) in $8(8 / 20 ; 40 \%)$ eyes and was associated with the thick hyperechoic retina and optic nerve (Figure $2 b$ and c) in $12(12 / 20 ; 60 \%)$ eyes. A vitreous detachment was seen in $7(7 / 20 ; 35 \%)$ eyes with vitreous bleeding.

The pus appeared as hypoechoic fluid filling the eyeball, which was settled at the bottom due to gravity leaving anechoic space behind the posterior lens capsule (Figure 2d). The retina appeared as a thick hyperechoic membrane under the settled hypoechoic fluid. The lens capsule appeared as incomplete hyperechoic lines indicating early cataractous changes. Based on the ultrasonographic evaluation, eye exenteration was performed in these cases. 


\section{Khaled M. Ali}

The conducted treatment protocol for eyes with corneal perforation and ultrasonographic appearance of low-reflectivity endovitreal echoes was conjunctival pedicle flap technique and systemic course of antibiotic ceftriaxone (ceftriaxone ${ }^{\circledR}$, Sandoz, Egypt) at a dose of $25 \mathrm{mg} / \mathrm{kg}$ i.m for seven days. Moxifloxacin hydrochloride $0.5 \%$ (Vigamox ${ }^{\circledR}$, Alcon, Egypt) and diclofenac sodium $0.1 \%$ (Epifenac $®$, EIPICO, Egypt) were used to control postoperative infection, pain and discomfort. Based on clinical and ultrasonographic characteristics of the eyes with corneal perforation and secondary optic neuritis, retinitis, vitreous hemorrhage/or detachment, eye evisceration and ocular prostheses using silicone oil combined with conjunctival pedicle flap were the selected methods of treatment (Figure 2e).

Buphthalmos and chronic glaucoma were diagnosed in $25(25 / 90 ; 27.77 \%)$ eyes. Eighteen eyes $(18 / 25 ; 72 \%)$ showed diffuse corneal edema and vascularization (Figure 3a), five eyes $(5 / 25 ; 20 \%)$ showed corneal edema, corneal vascularization and anterior synechia with a pupillary block (Figure $3 b$ ) and two eyes $(2 / 25 ; 8 \%)$ were presented with corneal abscessation and granulation tissue (Figure 3c) and corneal ulceration, pigmentation and vascularization (Figure 3d).

The ultrasonographic evaluation revealed an enlarged and misshapen globe (Figure 4a-d) in all cases with buphthalmos. Retinal detachment was observed in all eyes with buphthalmos was associated with a vitreous detachment in 20 eyes $(20 / 25 ; 80 \%)$. The type of retinal detachment recorded in these cases was mainly exudative and was shown as thick echogenic membrane/s that followed up to the optic nerve. The sub-retinal space appeared anechoic with floating hypoechoic dots (Figure 4b, c and d).In the cases with vitreous detachment, a hypoechoic membrane was formed leaving anechoic retro-vitreal space and was less echogenic than detached retinal membranes (Figure $4 c$ and d). Numerous mobile vitreal echoes of variable amplitude were also observed. Based on the ultrasonographic findings, all cases with buphthalmos were treated by the exenteration of the eyeball.

Phacoanaphylactic endophthalmitis was diagnosed in 15 (15/90; 16.66\%) eyes. All cases were presented with a hyper mature cataract. The cataractous lens was secondarily luxated in $8(8 / 15 ; 53.33 \%)$ eyes anteriorly, partially luxated in $4(4 / 15 ; 26.66 \%$ ) eyes and posteriorly luxated in $3(3 / 15 ; 20 \%)$ eyes. All cases of anterior lens-luxation were associated with secondary glaucoma. The ultrasonographic evaluation revealed that the cataractous dislocated lens was associated with endophthalmitis and enlargement of the globe (Figure 5a), vitreous detachment and hyperechoic floating dots were also seen inside the vitreous (Figure 5b). Posteriorly luxated lenses were well-visualized inside the vitreous (Figure 5c). Cases with partially dislocated lenses showed characteristic aphakic crescent and iris atrophy (Figure 5d) and the ultrasonographic pictures revealed vitreous detachment, hyperechoic floating dots and thickened iris tissue (Figure 5e).

The anteriorly dislocated lenses were removed via intra-capsular lens extraction (Figure 5f). The eyes with partial and posterior lens-luxation received only medical treatment in the form of topical eye drops every 8 to 12 hours for 14 days; tobramycin/ dexamethasone combination (Tobradex®; Alcon, Egypt) and pilocarpine hydrochloride 2\% (Isoptocarpine ${ }^{\circledR} 2 \%$, Alcon, Egypt). The treatment was applied to keep the lens in position and to minimize intraocular inflammation.

Iridocyclitis was diagnosed in 10 (10/90; $11.11 \%$ ) eyes and the recorded clinical findings were corneal edema, miosis, ciliary injection, conjunctival chemosis and episcleral injection. Secondary cataract and anterior synechia were seen in $3(3 / 10 ; 30 \%)$ eyes and glaucoma (angle-closure glaucoma) was diagnosed in $2(2 / 10 ; 20 \%)$ eyes.

In Five animals (5/10; 50\%) eyes, ultrasonographic examination revealed thickening and increased echogenicity of the ciliary body, iris tissue, globe wall and hyperechoic optic nerve with early cataractous changes (Figure 6a and b). The conducted treatment protocol for these cats included systemic dexamethasone sodium phosphate (Dexamethasone ${ }^{\circledR}$ $4 \mathrm{mg}$, Amriya Pharma IND, Egypt) $0.1 \mathrm{mg} / \mathrm{kg}$ IV at three days interval/ 4 injections and topical eye drops every 8 to 12 hours for 14 days; tobramycin/ dexamethasone combination and tropicamide1\% (Mydriacyl®, Alcon, Egypt).

Anterior synechia (Figure 6c), iris bombe (Figure 6d) and pupillary block glaucoma (Figure 6e) were diagnosed in 5 eyes out of 10 with iridocyclitis. Iridotomy was performed in three cats with iris bombe and two cats with pupillary block glaucoma. Clinical findings, ultrasonographic characteristics and treatment protocols of 60 cats (90 eyes) with endophthalmitis were summarized in Table 2. 


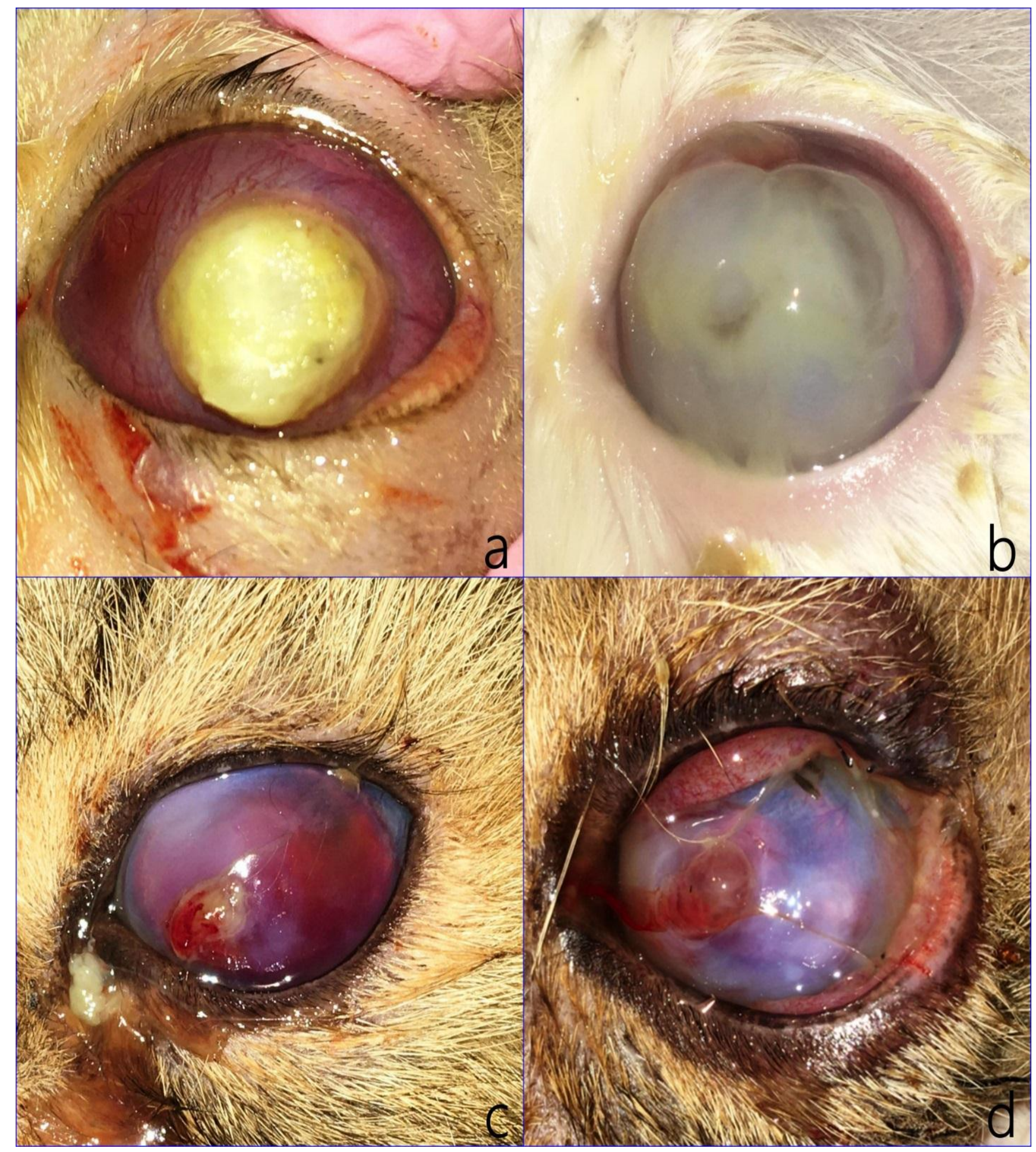

Figure 1: The clinical presentation of endophthalmitis secondary to corneal perforation. (a) Corneal vascularization, edema and large protruding fibrin clot sealing the corneal defect in 36 months-old Persian cats, (b) Corneal melting in 24 months-old DSH cat, (c) Cat claw injury with keratocoele, hyphema and corneal edema in 72 months-old DSH cat and (d) Conjunctival chemosis, keratocoele and collapsed anterior chamber in 18-months old DSH cat. 


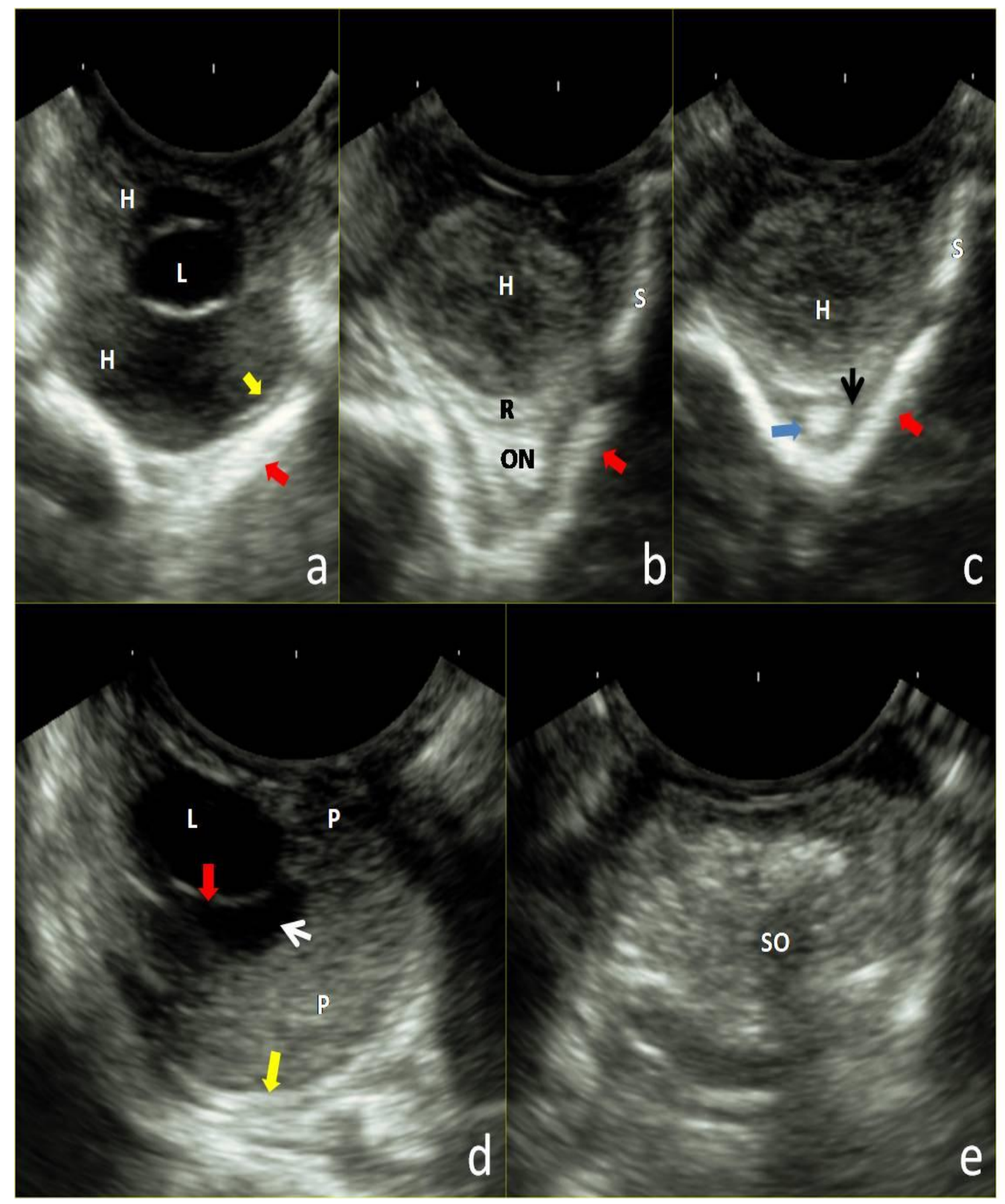

Figure 2: Trans-corneal (a), trans-scleral (b and c) ultrasonographic scans of the eyes with endophthalmitis secondary to corneal perforation showing vitreal hemorrhage $(\mathrm{H})$, hyperechoic thickened globe wall (red arrow), thickened retina (R), vitreal detachment (yellow arrow), thickened optic nerve $(\mathrm{ON})$ with surrounding anechoic space (blue arrow) filled with hypoechoic dots (black arrow). (d) Axial ultrasonographic scan showing pus $(\mathrm{P})$ in the anterior and posterior chamber with anechoic space under the lens (white arrow), early cataractous changes (red arrow) and thickened retina (yellow arrow). (e) Ocular prostheses with silicone oil (SO) filling the eviscerated eyeball. 


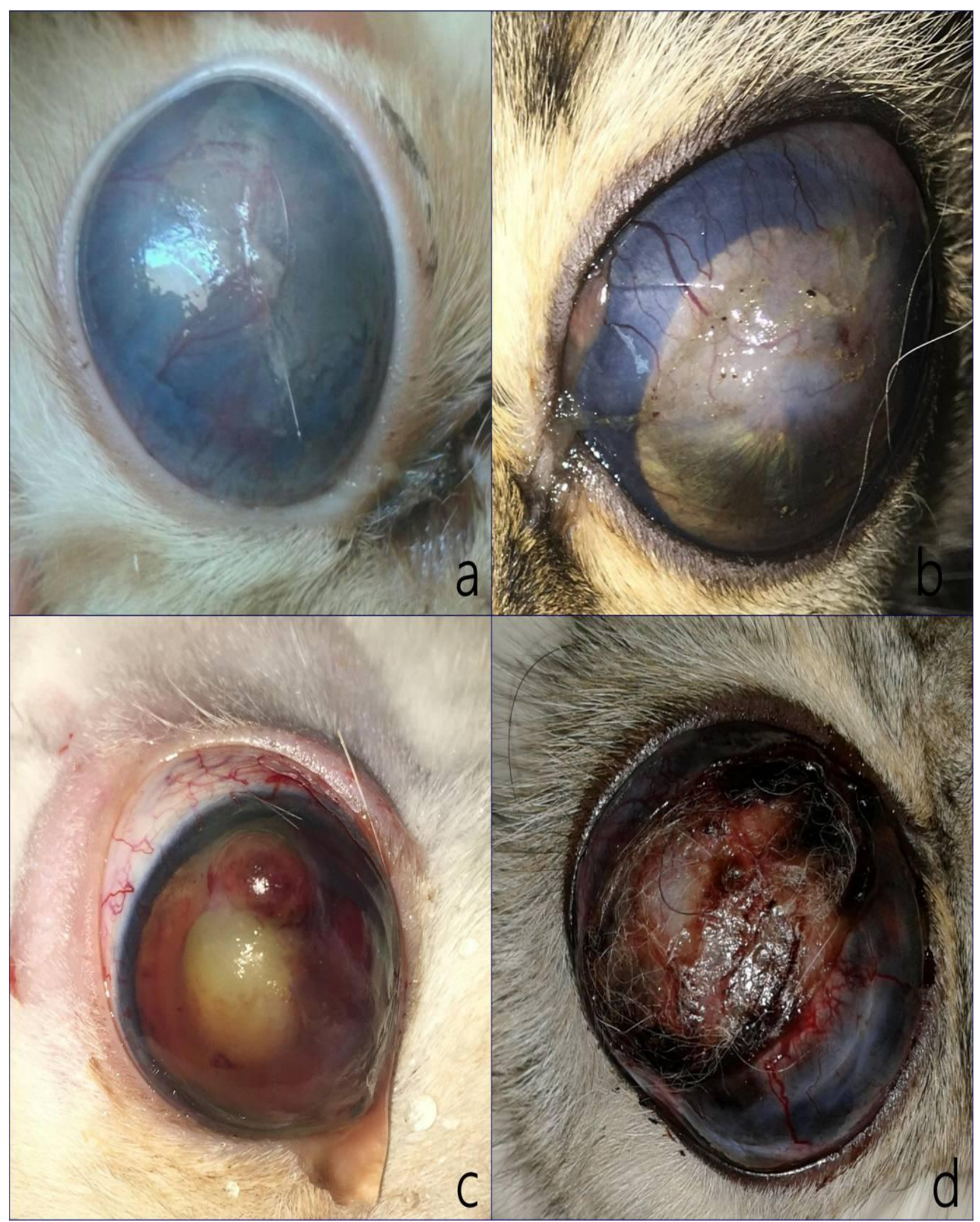

Figure 3: the clinical presentation of buphthalmos with diffuse corneal edema and vascularization (a), pupillary block glaucoma (b), corneal abscessation and granulation tissue (c) and corneal ulceration and pigmentation $(\mathrm{d})$. 


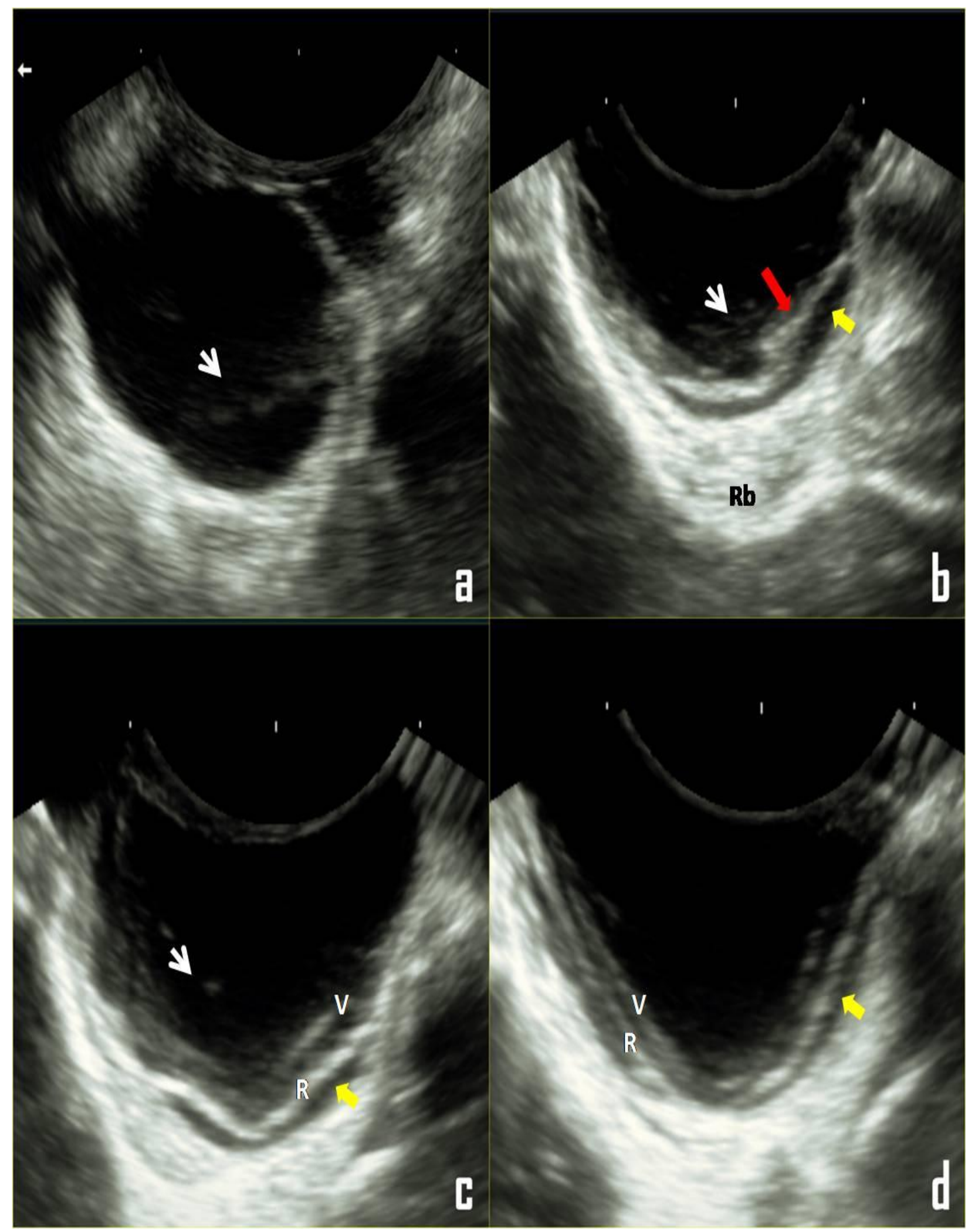

Figure 4: Trans-scleral ultrasonographic images showing enlarged misshapen globe (a-d), echogenic endovitreal echoes (white arrow), detached retina (R) retinal folds (red arrow), detached vitreous (V) and anechoic subretinal space filled with hypoechoic dots (yellow arrow). 


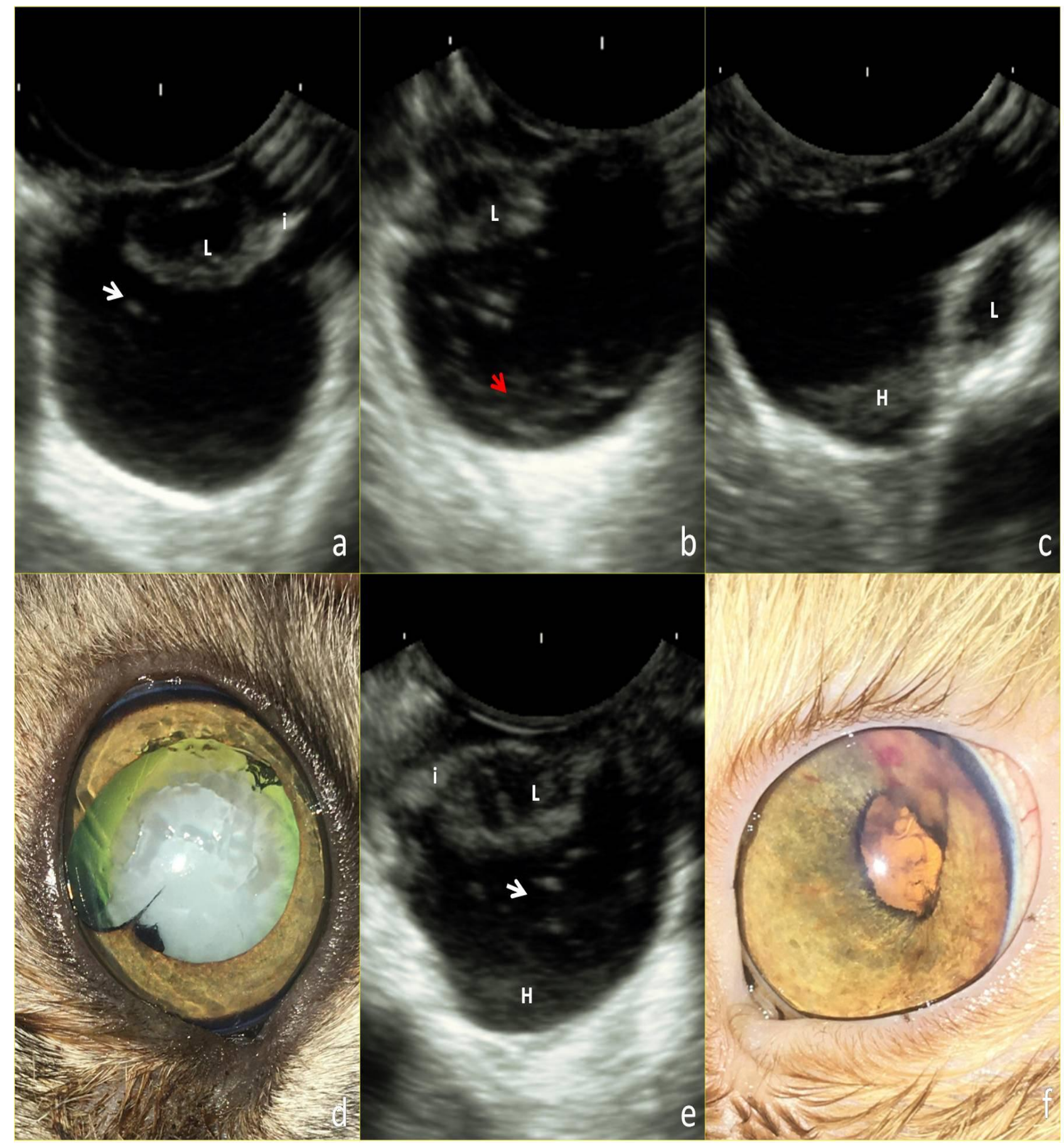

Figure 5: Trans-corneal ultrasonographic views showing anterior (a and b) and posterior (c) luxation of the cataractous lens (L), thickened iris (i), vitreal detachment (red arrow), vitreal hemorrhage $(\mathrm{H})$ and echogenic endovitreal dots (white arrow). (c) Partially luxated lens with clear aphakic crescent and iris atrophy. (d) Ultrasonographic image showing the phacoanaphylactic endophthalmitis accompanied the eyes with hyper mature cataract and partial lens luxation. (f) The eye of a Persian cat after successful lens extraction 


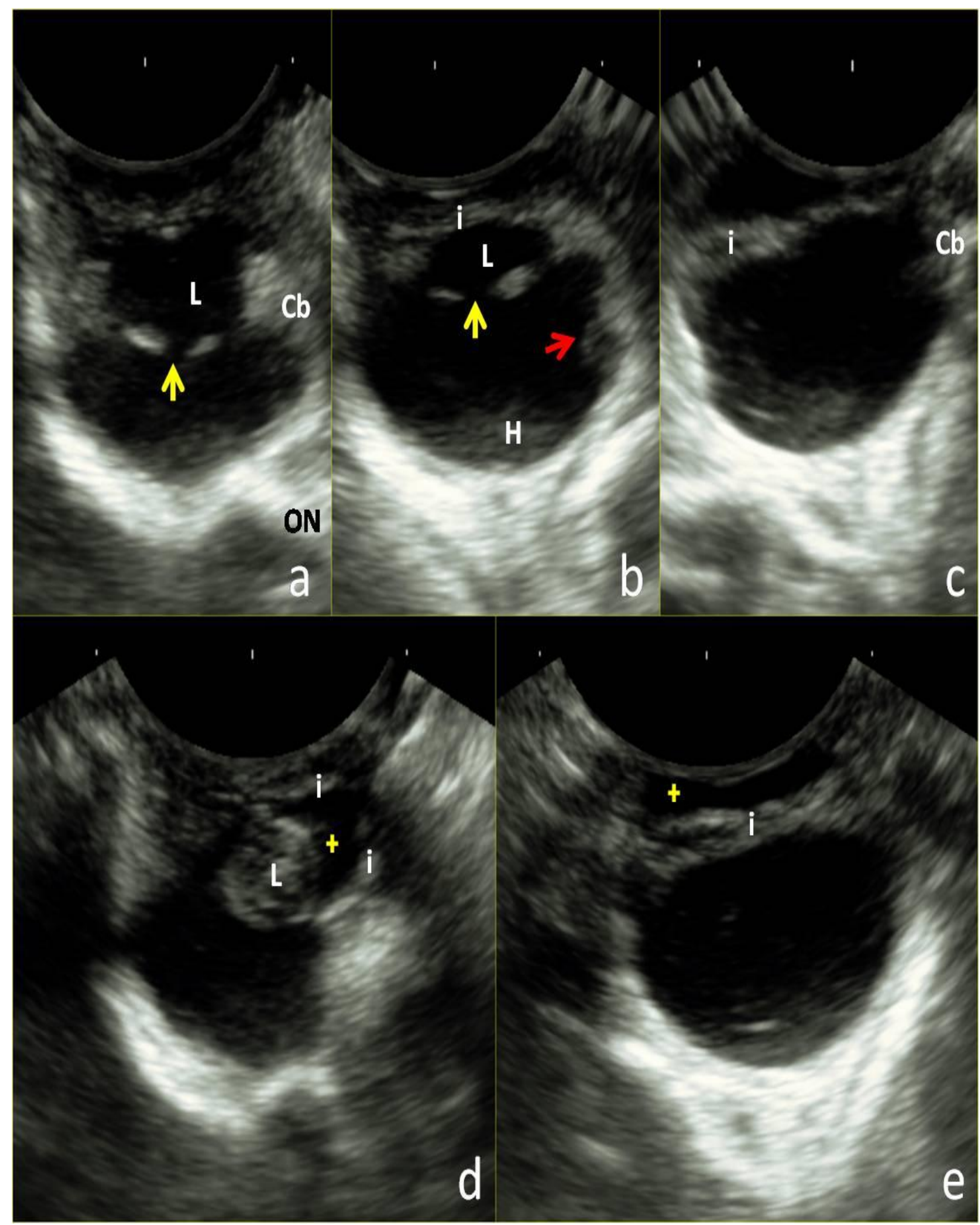

Figure 6: Trans-corneal views ( $a$ and $b$ ) of iridocyclitis and secondary endophthalmitis showing thickened ciliary body $(\mathrm{Cb})$, iris (i), early cataractous changes (yellow arrow), retinal folds (red arrow) and vitreal hemorrhage $(\mathrm{H})$. (c) Tangential view showing anterior synechia. (d) Iris bombe and echogenic cataractous lens with a deep anterior chamber (plus sign). (e) Tangential view showing pupillary block glaucoma and deep anterior chamber (plus sign). 
Table 1. Clinical findings, ultrasonographic characteristics of 60 cats with endophthalmitis

\begin{tabular}{ccc}
\hline Cause endophthalmitis & $\begin{array}{c}\text { Affected eye (No. of } \\
\text { cats) }\end{array}$ & Clinical findings
\end{tabular}

$\begin{array}{ll}\text { Both }(5 \text { cats }) & \text { Corneal melting, Corneal } \\ \text { OS }(2 \text { cats }) & \text { vascularization, Corneal edema } \\ \text { OD }(1 \text { cat }) & \end{array}$

Endovitreal hypoechoic patchy

OS (2 cats) vascularization, Corneal edema zones, Hyperechoic thickened

OD (1 cat) retina and thickened

hyperechoic optic nerve

\begin{tabular}{ll}
\hline Both (5 cats) & $\begin{array}{l}\text { Deep stromal ulcer, Keratocoele, } \\
\text { Corneal edema, Corneal vascularization } \quad \text { echoes }\end{array}$
\end{tabular}

Corneal perforation

(30 cats)

\begin{tabular}{ll}
\hline OD (4 cats) & Cat claw injury, Corneal edema, \\
& Corneal vascularization, Cornea defect \\
OS (3 cats) & sealed with fibrin clot, Hyphema
\end{tabular}

Endovitreal amorphous to hypoechoic patchy zones, Hyperechoic thickened retina and endovitreal membranes

\begin{tabular}{lll}
\hline OS (6 cats) & $\begin{array}{l}\text { Cat claw injury, Corneal perforation, } \\
\text { Large protruding fibrin clot over the } \\
\text { cornea defect, Corneal edema, Corneal } \\
\text { vascularization }\end{array}$ & $\begin{array}{l}\text { Homogenously non-movable } \\
\text { hypoechoic patchy zone filling } \\
\text { the eye ball (pus), Thickened } \\
\text { hyperechoic retina }\end{array}$
\end{tabular}

\begin{tabular}{|c|c|c|c|}
\hline \multirow{2}{*}{$\begin{array}{l}\text { Buphthalmos } \\
\text { (15 cats) }\end{array}$} & Both (9 cats) & $\begin{array}{l}\text { Unresponsive glaucoma, Diffuse } \\
\text { corneal edema, Corneal vascularization }\end{array}$ & $\begin{array}{l}\text { Misshapen globe, Thin globe } \\
\text { wall, Exudative retinal } \\
\text { detachment, Vitreous } \\
\text { detachment }\end{array}$ \\
\hline & OS (5 cats) & $\begin{array}{l}\text { Unresponsive glaucoma, Corneal } \\
\text { edema, corneal vascularization and } \\
\text { anterior synechia }\end{array}$ & $\begin{array}{l}\text { Misshapen globe. Exudative } \\
\text { retinal detachment }\end{array}$ \\
\hline \multirow{2}{*}{$\begin{array}{l}\text { Phacoanaphylactic } \\
\text { endophthalmitis } \\
\text { ( } 9 \text { cats) }\end{array}$} & Both (4 cats) & $\begin{array}{l}\text { Hypermature cataract, Anteriorly } \\
\text { luxated, cataractous lens, Secondary } \\
\text { glaucoma }\end{array}$ & $\begin{array}{l}\text { Low-reflectivity endovitreal } \\
\text { echoes, Vitreous detachment }\end{array}$ \\
\hline & Both (2 cats) & $\begin{array}{l}\text { Hypermature cataract, partially luxated } \\
\text { lens, iris atrophy and aphakic crescent }\end{array}$ & $\begin{array}{l}\text { Low-reflectivity endovitreal } \\
\text { echoes, Vitreal hemorrhage }\end{array}$ \\
\hline \multirow{3}{*}{$\begin{array}{l}\text { Iridocyclitis } \\
\text { ( } 6 \text { cats })\end{array}$} & $\begin{array}{l}\text { Both (2 cats) } \\
\text { OD (1 cat) }\end{array}$ & $\begin{array}{l}\text { Corneal edema, miosis, ciliary injection } \\
\text { and,conjunctival chemosis }\end{array}$ & $\begin{array}{l}\text { Thickening of the iris, } \\
\text { Thickened hyperechoic ciliary } \\
\text { body }\end{array}$ \\
\hline & Both (1 cat) & Secondary cataract, iris bombe & $\begin{array}{l}\text { Anterior synechia, Hypoechoic } \\
\text { lens }\end{array}$ \\
\hline & OS (1 cat) & & \\
\hline
\end{tabular}




\section{Khaled M. Ali}

Table 2. The treatment protocol conducted for sixty cats (90 eyes) with endophthalmitis

\begin{tabular}{|c|c|c|c|}
\hline Cause of endophthalmitis & $\begin{array}{l}\text { Number of } \\
\text { eyes }(\%)\end{array}$ & Associated findings & Treatment \\
\hline Corneal perforation & $13(32.5 \%)$ & Corneal melting & Eye evisceration and ocular prostheses \\
\hline \multirow{4}{*}{ (40 eyes) } & $10(25 \%)$ & Deep stromal ulcer & Conjunctival pedicle flap \\
\hline & $7(17.5 \%)$ & Cat claw injury & Eye evisceration and ocular prosthesis \\
\hline & & Cat claw injury with pus & \\
\hline & $10(25 \%)$ & inside the eyeball & Eye exenteration \\
\hline \multicolumn{4}{|l|}{ Buphthalmos } \\
\hline (25 eyes) & $25(100 \%)$ & Unresponsive glaucoma & Eye exenteration \\
\hline \multirow{3}{*}{$\begin{array}{l}\text { Phacoanaphylactic } \\
\text { endophthalmitis } \\
\text { (15 eyes) }\end{array}$} & $8(53.33 \%)$ & Anteriorly luxated lens & Intracapsular lens extraction \\
\hline & $4(26.66 \%)$ & Posteriorly luxated lens & Miotics, Topical corticosteroids \\
\hline & $3(20 \%)$ & Partially luxated lens & Miotics, Topical corticosteroids \\
\hline \multirow{3}{*}{$\begin{array}{l}\text { Iridocyclitis } \\
\text { (10 eyes) }\end{array}$} & $5(50 \%)$ & - & Corticosteroids Mydriatics \\
\hline & $3(30 \%)$ & Iris bombe, cataract & Iridotomy,Corticosteroids, ydriatics \\
\hline & $2(20 \%)$ & Pupillary block glaucoma & Iridotomy, Corticosteroids \\
\hline
\end{tabular}

\section{DISCUSSION}

Endophthalmitis is commonly seen in the veterinary patients in the course of a corneal ulcer (Brooks and Matthews, 2007) or as a perforating eye injury (Spiess et al., 1996). Clinical diagnosis of endophthalmitis is based on major signs of inflammation in the anterior segment of the eyeball. However, incomplete visualization of the eye due to the development of ocular opacities limits the use of ophthalmoscopy and slit-lamp biomicroscopy (Scotty et al., 2004 and Mackay and Mattoon, 2015). In these cases, ultrasonography may prove useful for determining the severity and extent of ocular involvement. Furthermore, no studies have correlated the ultrasonographic characteristics of endophthalmitis in cats to the selected treatment protocol.

The present study documented various types of ocular abnormalities in the course of endophthalmitis in cats. In addition, the correlation between the clinical and ultrasonographic findings was also reported and the treatment protocol for every condition was conducted.

In this study, trans-corneal scanning provided reliable images of the posterior segment of the globe
(Mackay and Mattoon, 2015 and Singh et al., 2015) and imaging through the eyelid was avoided to limit artifacts or image degradation. The used high transducer frequencies $(7.5-10 \mathrm{MHz})$ allowed for superior resolution of the posterior segment with focal zones of $2-5 \mathrm{~cm}$ (Williams and Wilkie, 1996). Moreover, the used tangential approach and transscleral approach were useful for visualization of the anterior structures and posterior structures, respectively (Schmid, 2007).

The chronic leakage, prolonged hypotony and a collapsed anterior chamber after perforating ocular injuries contribute to endophthalmitis and severe intraocular hemorrhage (Mancuso et al., 2016). In viewing the present study results, endophthalmitis was secondary to corneal perforation in 40 eyes (44.44\%). Numerous ultrasonographic features have been reported including; intraocular hemorrhage in 20 (50\%) eyes, pus inside the eyeball in $10(25 \%)$ eyes and lowreflectivity endovitreal echoes in $10(25 \%)$ eyes. The recorded endovitreal echoes were attributed to the infiltration, invasion and agglomeration of inflammatory cells inside the vitreous compartment (Schmid, 2007). Intraocular hemorrhage appeared as amorphous opacities to hypoechoic patchy zones filling the anterior and posterior chamber. The heterogeneous 
echogenicity was attributed to the organization of the vitreal bleeding (Wilke and Gilger, 1998 and Schmid, 2007). A vitreous detachment was seen in 7 (7/20; $35 \%$ ) eyes with vitreous bleeding and was characterized by anechoic retrovitreal space (Schmid, 2007).

A poor prognosis for vision is associated with vitreal hemorrhage (Cho et al., 1998) because of the development of tractional retinal detachment, posterior synechia (Morgan, 1982), peripheral anterior synechia, secondary glaucoma, cataract formation(Nelms et al., 1993) and phthisis bulbi (Crouch and Crouch, 1999). Regarding the results of the present study, the ultrasonographic examination of 20 eyes after corneal perforation revealed well-organized vitreal bleeding filling the whole vitreous compartment associated with the thick hyperechoic retina and optic nerve in 12 $(60 \%)$ eyes and vitreous detachment in $7(35 \%)$ eyes. These eyes were not potential for vision and the conducted treatment protocol was eye evisceration combined with intraocular prostheses, as required by the owners. The ocular contents were eviscerated through the trans-corneal approach and the silicone oil (Peña et al., 1997) was then injected inside the globe to match the size of the opposite eye. A conjunctival pedicle flap technique was applied to close the corneal defect. After removal of the conjunctival flap, these cats responded extremely well with an attractive-ocular appearance.

However, the ultrasonographic examination of 10 eyes with corneal perforation due to cat claw injury revealed the presence of a homogenously non-movable hypoechoic patchy zone filling the eyeball (pus) with the thickened hyperechoic retina. In these eyes, ocular prostheses were not performed because of the intraocular infection and eye exenteration was the conducted method of treatment (Miller, 2008a).

Buphthalmos and endophthalmitis secondary chronic untreatable glaucoma were recorded in 25 $(27.77 \%)$ eyes. The associated clinical findings were diffuse corneal edema, anterior synechia with pupillary block and corneal abscessation with corneal granulation tissue. All these findings necessitated the use of ultrasonography to evaluate the internal structures of the eyeball. All cases of buphthalmos were associated with a retinal detachment associated with a vitreous detachment in 20 eyes $(80 \%)$. However, the type of the retinal detachment was mainly exudative due to the extensive intra-ocular inflammatory process, which was proven by the presence of floating hypoechoic dots in the sub-retinal space (Schmid, 2007). The detached retina membranes appeared as diffuse thick echogenic membranes that followed up to the optic nerve. This was in agreement with (McLeod et al., 1977), who described the detached retina as a regular continuous sheet of highamplitude echoes. The retina is usually attached firmly to the points of the ora serrata anteriorly and the optic nerve head posteriorly. The exenteration of the eyeball was performed in all eyes with buphthalmos based on the clinical and ultrasonographic appearance. Ocular prostheses were not performed to these cats due to the thin ocular wall and the misshapen enlarged globe.

Cataracts are degenerative changes that produce echogenicity at various locations within an anechoic lens. Cataract can be easily diagnosed from the clear clinical signs and leukocoria and by the aid of ophthalmoscopy and slit-lamp biomicroscopy (Gelatt and Mackay, 2005). However, echogenicity, size and shape of the lens may change with the type of cataract and its duration (Spaulding, 2008). Moreover, lensinduced uveitis, lens luxation and secondary glaucoma are common complications to hypermature cataract due to the phacoanaphylactic response to lens material (Collins and Moore, 1999). In addition, Lens-induced uveitis can be clinically evident or subclinical in cataractous patients (Gelatt and MacKay, 2005).In this study, ultrasonography was useful to diagnose the posterior segment involvement in cases with phacoanaphylactic endophthalmitis and lens luxation. The technique evaluated the position of the luxated lenses properly and the posterior segment findings were vitreous detachment and hyperechoic floating dots inside the vitreous chamber.

Regarding the results of the iridocyclitis, ultrasonography was practical in the selection of the appropriate method of treatment. Medicinal treatment was applied on five eyes to reduce the intraocular inflammatory process and to prevent possible complications. Surgical treatment was applied on five cats to correct the encountered complications as anterior synechia, iris bombe and secondary glaucoma (Miller, 2008b). Satisfactory results were obtained after treatment of all cats enrolled in this study with 1-3 months of observation and followed up. The recorded complications included mild to moderate degrees of corneal scarring (Ali and Hassan, 2020) in 5 eyes treated with conjunctival flap, persistent corneal edema in 2 eyes after intra-capsular lens extraction and in 3 eyes after iridotomy.

The most important limitation of the present study was the lack of histopathologic evidence to confirm the ultrasonographic diagnoses. Another limiting factor was the lack of correlation between the course of endophthalmitis and the ultrasonographic findings. Future studies should address both concerns. 


\section{CONCLUSIONS}

In conclusion, the use of ultrasonography as an adjunct tool to assess the concurrent ocular abnormalities associated with different types of endophthalmitis in cats is very helpful in accurate diagnosis and for the selection of the treatment protocol.

\section{Declaration of Conflicting Interests}

The author declared no potential conflicts of interest with respect to the research, authorship, and/or publication of this article.

\section{Funding}

The author received no financial support for the research, authorship, and/or publication of this article.

\section{REFERENCES}

ALI, K.M. AND HASSAN, M.H. 2020.Visual outcome evaluation of complicated perforating corneal injuries after surgical repair in 45 cats. Turkish Journal of Veterinary And Animal Science, In press.

BROOKS, D. E. AND MATTHEWS A. G. 2007. Equine ophthalmology. In: Gelatt KN, ed. Veterinary Ophthalmology. 4th ed. Ames, Iowa: Blackwell Publishing, 165-1274.

CHO, J., JUN, B. K., AND LEE, Y. J. ET AL., 1998. Factors associated with the poor final visual outcome after traumatic hyphema. Korean J Ophthalmol., 12:122-129.

COLLINS, BK AND MOORE, CP 1999. Diseases and surgery of the canine anterior uvea. In: Veterinary Ophthalmology, 3rd ed. (ed. Gelatt KN) Lippincott, 522 Williams and Wilkins, Philadelphia, 755-795.

CROUCH, ER AND JR, CROUCH, E. R. 1999. Management of traumatic hyphema: Therapeutic options. J Pediatr Ophthalmol Strabismus, 36:238-250.

DAR, M. ET AL., 2014. B-scan ultrasonography of ocular abnormalities: A review of 182 dogs. IJVR, 15: 122126

DOUET, JY, MICHEL, J AND REGNIER, A. 2013. Degree and duration of corneal anesthesia after topical application of $0.4 \%$ oxybuprocaine hydrochloride ophthalmic solution in ophthalmically normal dogs. Am J Vet Res. 74:1321-1326

ESSON, DW, 2015. Endophthalmitis and panopthalmitis. In: Clinical Atlas of Canine and Feline Ophthalmic Disease, 1 st ed. Published by John Wiley \& Sons, Inc. 280-281.

https://doi.org/10.1002/9781118840801.ch133

FEATHERSTONE, HJ AND HEINRICH CL 2013. Ophthalmic examination and diagnostics. In: Gelatt KN, Gilger BC, Kern TJ (eds).Veterinary Ophthalmology. Vol 1. 5th ed. Ames, IA, USA: WileyBlackwell/John Wiley \& Sons. Pp. 671-683.

FIELDING, J. A. 2001. The eye and orbit. In: Meire, HB; Cosgrove, DO; Dewbury, KC and Wilde, P (Eds.), Clinical ultrasound. (2nd Edn.), Edinburgh, Churchill Livingstone. PP: 938-964.
GELATT, K. AND MACKAY, E. 2005. Prevalence of primary breed related cataracts in the dog in North America. Vet. Opthalmol., 8: 101-111.

GIALLETTI, R., MARCHEGIANI, A., VALERIANI, T. ET AL., 2018. A survey of ocular ultrasound abnormalities in horse: 145 cases. Journal of Ultrasound. 21:53-59. doi: 10.1007/s40477-018-02847

GUYONNET, A. ET AL., 2019. Supposed endogenous endophthalmitis caused by Serratia marcescens in a cat. Open Veterinary Journal, (2019), Vol. 9(1): 13-17. DOI: http://dx.doi.org/10.4314/ovj.v9i1.3

KOHANIM, S., DANIELS, AB AND HUYNH, N. ET AL., 2012. Utility of ocular ultrasonography in diagnosing infectious endophthalmitis in patients with media opacities. Semin Ophthalmol. 27(5-6):242-5.doi: 10.3109/08820538.2012.711417.

MACKAY, CS AND MATTOON, JS 2015. Eye. In: Mattoon JS, Nyland TG, editors. Small Animal Diagnostic Ultrasound. 3rd ed. St. Louis, MO, USA. Saunders Elsevier. Pp. 130-154.

MAMALIS, N., KEARSLEY, L. AND BRINTON E. 2002. Postoperative endophthalmitis. Curr Opin Ophthalmol. 13(1):14-18.

MANCUSO, LA, LASSALINE, M. AND SCHERRER, NM 2016. Porcine urinary bladder extracellular matrix grafts (ACell Vet Corneal Discs) for keratomalacia in 17 equids (2012-2013). Veterinary Ophthalmology; 19 (1): 3-10. doi: 10.1111/vop.12240.

MARCHINI, G.,PAGBARUSCO, A., TOSI R., AND CASTAGNA G. 1995. Ultrasonographic findings in endophthalmitis. Acta Ophthalmol. Scand. 73: 446-449.

MCLEOD, D., RESTORI, M. AND WRIGHT, J., 1977. Rapid B-scanning of the vitreous. Bri. J. Ophthalmol., 61: 437-445.

MILLER, P. E. 2008a. Orbit. In: Slatter's fundamentals of veterinary ophthalmology. (eds. Maggs D, Miller P, Ofri R). $4^{\text {th }}$ edn. Saunders-Elsevier, St. Louis, Missouri, pp 352-373.

MILLER, P. E. 2008b. Glaucoma. In: Slatter's fundamentals of veterinary ophthalmology. (eds. Maggs D, Miller P, Ofri R). $4^{\text {th }}$ edn. Saunders-Elsevier, St. Louis, Missouri, pp 352-373.

MORGAN, R. V. 1982. Ocular emergencies. Compend Contin Educ Pract Vet; 4:44.

NAUTRUP, CP AND TOBIAS, R. 2000. An atlas and textbook of diagnostic ultrasonography of the dog and cat. London, UK, Manson Publishing Ltd., PP: 92-108.

NELMS, SR, NASISSE, M. P. AND DAVIDSON, M. G. ET AL., 1993. Hyphema associated with retinal disease in dogs: 17 cases (1986-1991). J Am Vet Med Assoc., 202:1289-1292.

NYLAND, TG, AND MATTOON J. S. 1995. Veterinary diagnostic ultrasound. W.B. Saunders company. PP.178-197.

PEÑA, M.T., LUERA, M., GARCÍA, FA. 1997. A new type of intraocular prosthesis for dogs Veterinary Record 140, 67-68.

SCHMID, V. 2007. Imaging of the Eye and Orbit. In: Diagnostic Ultrasound in Small Animal Practice. Blackwell Science Ltd, pp.278 - 300 . DOI: $\underline{10.1002 / 9780470752357 . c h 14}$ 
SCOTTY, NC, CUTLER, TJ, AND BROOKS DE ET

AL., 2004. Diagnostic ultrasonography of equine lens and posterior segment abnormalities. Vet. Ophthalmol. 7: 127-139. doi: 10.1111/j.14635224.2004.04009.x

SINGH, S., PUROHIT, S. AND PANDEY, RP (2015). Bmode intraocular echo-morphometry of Murrah buffalo (Bubalus bubalis). Ruminant Science 4(2):249-254.

SINGH, S., PUROHIT, S., MALIK, V., YADAV, S., SINGH, RK, GANGWAR, NK. AND PANDEY, RP (2016). Echo-morphometric evaluation of ocular affections in Murrah buffaloes: Review of 15 cases. Ruminant Science 5(1):117-122.

SPAULDING, K. 2008. Eye and orbit. In: Pennieck, D and d'Anjou, MA (Eds.), Atlas of Small Animal Ultrasonography. (2nd Edn.), Iowa, Blackwell Publishing. PP: 49-89.

SPIESS, B. M., FUHLI, M. R. AND BOLLINGER, J. 1996. Eye injuries from cats claw at dog (in German). Schweizer Archiv fur Tierheilkunde 138, 429-433.

WILKE, D. A. AND GILGER, BC 1998. Equine diagnostic ocular ultrasonography, In Rantanen NW,
McKinnon AO. Eds. Equine Diagnostic Ultrasonography. Baltimore: Williams \& Wilkins, pp. 637-643.

WILLIAMS, J. AND WILKIE, D. A. 1996. Ultrasonography of the eye. Compend Contin Educ Pract Vet; 6:667-676.

How to cite this article:

Khaled M. Ali, 2020. Role of Ultrasonography In the Diagnosis and Management of Endophthalmitis in Cats. Journal of Applied Veterinary Sciences, 5(3): 57 - 70.

DOI: HTTPS://DX.DOI.ORG/10.21608/JAVS.2020.98376 